only one positive in 16 . In the $B 2$ group the presenco of cells was excluded by filtration of all materials injected, and the number of positive results (2 in 39) which occurred, although low, was higher than that (2.5 per cent) found in earlier experiments with tumour filtrate alone ${ }^{3}$. The much smaller number of tumours in $B 2$ than $A 2$ may be due, if contamination with cells in $A 2$ can be excluded, to a considerable reduction in the amount of some tumour-producing agent caused by : $(a)$ loss of the agent on the mem. brane and filter apparatus; (b) oxidation taking place during prolonged collection of the bile and filtration.

Research Institute,

L. Donothy Parsons.

Royal Cancer Hospital (Free),

Fulham Road,

London, S.IV.3.

June 3.

${ }^{1}$ Cook, J. W., J. Chem. Soc., 3277 (1931).

' Clarkson, J. R., Mayneord, W. V., and Parsous, L. D., J. I'ath. and Bact., 48, 221 (1935).

- Parsons, L. D., J. Path, and Bact., 43, 1 (1936).

\section{Autocatalysis and Blood Coagulation}

Trre autocatalytic behaviour of blood coagulation is thought, by several authors, to be due to the autocatalytic formation of thrombin from its precursor prothrombin ${ }^{1}$. So far, thrombin seems similar to the enzymes studied by Northrop and co-workers ${ }^{2}$.

Experiments have now shown the reaction to bo a more complicated one. In a neutralized solution containing purified fibrinogen and prothrombin, together with calcium chloride, it was not found possiblo to obtain a formation of new thrombin upon inoculation with preformed thrombin. By inoculation from such a mixture to a new solution, and so on, the clotting power was exhausted in the course of a fow passages, which is in contrast to the results obtained with fresh plasma as a clotting medium ${ }^{3}$. The clotting power of the mixture was in accordance with the amount of thrombin added, and only the further addition of thrombokinase yielded new amounts of thrombin. In fresh plasma it was possible, by the addition of small amounts of acetic acid, to inhibit the autocatalytic properties.

Thrombin thus does not seem to be formed by an autocatalytic reaction in the common sense, and the autocatalysis takes place only in native plasma.

Biological Institute,

Carlsberg Foundation, TAGE AstruP.

\section{Copenhagen,} June 6.

1 Gratia, A., and Fredericq, P., C.R. Soc. Biol., 126, 906 (1937).

Compare Northrop, J. H., J. Gen. Physiol., 21, 335 (1933).

'Fischer, A., Nature, 135, 1075 (1935).

\section{Isolation of Oestrone from the Adrenal Gland}

Is a former communication to Nature ${ }^{1}$ reporting the isolation of progesterone and allopregnanolone from the adrenal gland, reference was made to the work of Engelhart ${ }^{2}$. He obtained lipoid extracts of this gland which produced oestrous and progestational effects in the uterus of the immature rabbit. Later, Callow and Parkes ${ }^{3}$, who confirmed theso findings, fractionated the active materials by the method of Allen and Moyer.

Now a further investigation of the oestrogenic principlo of the adrenal has been made, using a concentrato kindly supplied by N. V. Organon Oss to Dr. A. S. Parkes, who placed it at my disposal.

The concentrate, from which the adrenalin and the greater part of the cortical hormone group of steroids had been removed, was saponified, practically all the oestrogenic activity being found in the saponifiable material. This was separated into nonketonic and ketonic fractions, both of which were oestrogenic. Oestrone has been isolated from the latter as the benzoate, melting at $215-217^{\circ}$ alone or at $215-216^{\circ}$ when mixed with authentic oestrone benzoate (melting point $215-217^{\circ}$ ).

A bioassay on the isolated benzoate, carried out by Mr. Emmens of the National Institute for Medical Research, gave an 80 per cent response in a group of ten mice, each receiving a single dose of $0.5 \gamma$ in nut oil. Authentic oestrone benzoate under similar conditions gave a 90 per cent response.

Full experimental details of the isolation of the oestrone will be published in full elsewhere. The oestrogenic material in the non-ketonic fraction is still under investigation.

\section{BeALL.}

(Beit Memorial Fellow.)

British Postgraduate Medical School,

London.

June 8.

1 Beall, D., and Relchstein, T., NATURE, 142, 479 (1933).

'Engelhart, E., Klin. Wochr., 9, 2114 (1930).

Callow, R. K., and Parkes, A. S., J. Physiol., 87, $23 P$ (1936).

- Allen, W. M., and Meyer, IR. K., Amer. J. Physiol., 108, 55 (1933).

\section{Precipitation of Protein Fractions in Solutions} Particularly Poor in Proteins

THere are some technical difficulties in the handling of small amounts of protein fractions precipitated with neutral salts, such as sodium sulphate, in the usual way, because of the comparatively large quantities of liquid to be employed. Wo havo theroforo mado attempts to find a method permitting the precipitation of the different proteins by direct addition of the salt to the protein solutions in tho desired proportion.

Experiments have been made with human blood serum as well as with virus solutions of Shope rabbit papilloma. As a control, we employed the usual method of precipitation : addition of 30 parts of the salt solution in the desired concentration to 1 . part of protein solution. After allowing to stand for about three hours, filtration was performed through Schleicher-Schüll No. 602 filters; the total and residual nitrogen content in the filtrates was controlled by micro-Kjeldahl estimations.

For the new method wo added a weighed amount of the dry, well-powdered salt (sodium or ammonium sulphate) extremely slowly to the protein solution with continuous shaking, avoiding in this way an abrupt increase of concentration; if necessary the manipulation was carried out in a water-bath. 'Thus we needed about 30 minutes for dissolving $1.5 \mathrm{gm}$. in 5 c.c. of protein solution. Three hours afterwards, filtration and estimation were done as usual.

By this method a quantitative yield of the precipitated protein can easily bo obtained, and sedimentation of large amounts of liquid in big centrifuges can often bo avoided.

Cancer Research Laboratory, Peter Ladewig. University, Istanbul. June 1. 